\title{
Psychosocial Impact of Irritable Bowel Syndrome Among Teachers in Tabuk, Saudi Arabia
}

\author{
Hyder Mirghani ${ }^{1,}$, , Abdulateef Elbadawi ${ }^{2}$, Talal Khalid Alanazi ${ }^{3}$, Abdulaziz Hamoud Alanazi ${ }^{3}$, \\ Abdullah Gblan Alrashidy ${ }^{3}$, Mohammed Saleh Alshehri ${ }^{3}$, MeshalFaleh Alenezi ${ }^{3}$ \\ ${ }^{1}$ Medical Department, Faculty of Medicine, Tabuk University, Tabuk, Saudi Arabia \\ ${ }^{2}$ Community Medicine Department, Faculty of Medicine, Tabuk University, Tabuk, Saudi Arabia \\ ${ }^{3}$ Medical Interns, Faculty of Medicine, Tabuk University, Tabuk, Saudi Arabia
}

Email address:

h.mirghani@ut.edu.sa (H. Mirghani), abdulateefe@yahoo.com (A. Elbadawi), Al-faqeery@hotmail.com (T. K. Alanazi)

${ }^{*}$ Corresponding author

\section{To cite this article:}

Hyder Mirghani, Abdulateef Elbadawi, Talal Khalid Alanazi, Abdulaziz Hamoud Alanazi, Abdullah Gblan Alrashidy, Mohammed Saleh Alshehri, MeshalFaleh Alenezi. Psychosocial Impact of Irritable Bowel Syndrome Among Teachers in Tabuk, Saudi Arabia. American Journal of Internal Medicine. Vol. 5, No. 2, 2017, pp. 18-21. doi: 10.11648/j.ajim.20170502.11

Received: February 7, 2017; Accepted: February 18, 2017; Published: March 9, 2017

\begin{abstract}
In the present study, we aimed to study the psychosocial impact of irritable bowel syndrome among Saudi teachers in Tabuk. Across-sectional descriptive study was conducted among 362 teachers randomly selected from a total number of 60 schools in Tabuk City during the period January 2015 to June 2015. Participants were invited to sign a written informed consent, then responded $\mathrm{t}$ a structured questionnaire to collect socio-demographic factors, absence from work or sick leave due to IBS symptoms, partner employment, house type (own vs. rent), income, income adequacy, participation in care of children, continuous stress, excessive, and sleeping hours. Irritable bowel syndrome patients were more likely to be absent from work, took sick leave, and had more stress than those without the syndrome P-value $<0.05$, no differences were evident between irritable bowel syndrome patients and healthy participants regarding income, house type, residency, level of exercise, smoking and sleeping hours P-value $>0.05$. Irritable bowel syndrome patients were more prone to stress, absent from work, and took more sick leave than those without the syndrome. Screening for and the earlier detection of workers with irritable bowel syndrome could alleviate stress save working hours.
\end{abstract}

Keywords: Psychosocial, Irritable Bowel, Teachers, Saudi Arabia

\section{Introduction}

Irritable bowel syndrome is a common diagnosis in gastroenterology and primary care clinics with a burden to society through cost, quality of life impairment, and reduced social functioning [1]. Many factors are to blame in the etiology of irritable bowel syndrome including altered pain perception, gut motility, and the brain-gut axis, psychological and social factors can influence the disease presentation and outcomes [2]

In the United States of America, irritable bowel syndrome is one of the leading causes of financial burden; some studies pointed to 30 billion Dollars annually from direct and indirect costs [3].

In patients younger than 50 years of age without the following alarm features: weight loss, family history of certain organic diseases like inflammatory bowel diseases and rectal cancers, and iron deficiency anemia, laboratory testing is not recommended for the diagnosis of irritable bowel syndrome [4]

Clinical and experimental studies demonstrated that psychological stress either acute or chronic during childhood or adult life substantially affect intestinal sensitivity, motility, secretion and permeability, and the underlying mechanism has a close correlation with mucosal immune activation [5].

The data about the psychosocial impact of irritable bowel syndrome is scarce in Tabuk, Saudi Arabia, so we conducted this research. In the present study we aimed to investigate the Psychosocial Impact of Irritable Bowel Syndrome among Teachers in Tabuk-Saudi Arabia. 


\section{Subjects \& Methods}

This cross-sectional study conducted among 362 teachers randomly selected from a total number of 60 schools [total number of teachers]. In Tabuk City during the period January 2015 to June. The irritable bowel syndrome was diagnosed using the Rome 111 Criteria. The Rome 111 Criteria for the diagnosis of irritable bowel give specificity of 0.7-0.9, and sensitivity of 0.4-0.9 depending on the physician experience $[10,11]$.

According to the Rome III Committee, the irritable bowel syndrome is defined as the fulfillments of the following:

- Recurrent abdominal pain or discomfort for at least three days/month in the last three months ' (discomfort' is defined as an uncomfortable sensation, not pain)

- Symptom onset, at least, 3 months before diagnosis

- The symptoms are associated with two or more of the following

1. Pain decreasing or disappearing with defecation

2. Onset of pain related to a change in the frequency of stool

3. Onset of pain associated with a change in the form (appearance) of stool

without any underlying systemic, organic or metabolic causes [12]. A structured questionnaire was used to collect sociodemographic factors, absence from work or sick leave due to IBS symptoms, partner employment, house type (own vs. rent), income, income adequacy, participation in care of children, continuous stress, excessive, and sleeping hours.

The ethical committee of the University of Table approved the research, and the Statistical Package for Social Sciences was used for data analysis, data were presented as percentages or mean $\pm \mathrm{SD}$, the Chi-square test was used to compare variables and a $\mathrm{P}$-value $<0.05$ considered significant.

\section{Results}

They were three hundred sixty-two teachers; their ages ranged from 20-60 years with a mean of (), 59.9\% were females, $301(84.8 \%)$ were married, 39 (11\%) were single, 9 $(2.5 \%)$ were divorced while $6 .(1.7 \%)$ were widows. Table (1) showed other subjects characteristics.

The current data showed that 103 (28.7\%) of the participant were absent from the work due to the disease, and $126(35.1 \%)$ took sick leave due to the disease symptomatology. Less than half: $162(44.9 \%)$ live in their house, 209 (60.6\%) had their partner employed, more than two-thirds had a salary of more than 5000 Saudi Riyals, 15.3\% had extra income, while253 (70.5\%) felt that their income is adequate. Stress was documented in $77.8 \%$ of the participant with $15.6 \%$ had persistent stress, $46 \%$ of teachers sleep less than 6 hours per night, smoking was found in $14.1 \%$ of them while a minority $8.9 \%$ were on regular exercise program Table (2).

No significant statistical difference was evident between those with IBS positive and IBS negative participants regarding salary less than 5000 Saudi Riyals (4\% vs.4.2\%) Pvalue 0.967 , extra-income (13.7\% vs. $15.6 \%) \mathrm{P}$-value 0.773 , or income adequacy (64.7\% vs.71.4) P-value 0.325 .

The participant with irritable bowel syndrome was more likely to be absent from work and took sick leave than those without the syndrome (52.9\% vs. $24.7 \%$, and $68.6 \%$ vs. $29.5 \%$ respectively) P-value $<0.001$. Persistent stress was commoner in irritable bowel syndrome than those without (13.7 vs.5.5\%) P-value 0.020. Table (3) depicted other subjects characteristics.

In the current study, hypertension was found in $27(7.3 \%)$ of participants, diabetes in $14(4 \%)$, while bronchial asthma was found in 14 (4\%) of subjects. Table (4) illustrated other chronic diseases among the study group.

Table 1. Characteristics of the study group.

\begin{tabular}{ll}
\hline Character & No\% \\
\hline Age years & \\
$20-29$ & $62(17.2 \%)$ \\
$30-39$ & $225(62.3 \%)$ \\
$40-49$ & $68(18.8 \%)$ \\
$50-60$ & $6(1.7 \%)$ \\
Sex & \\
Males & $145(40.1 \%)$ \\
Females & $217(59.9 \%)$ \\
Marital status & \\
Married & $301(84.8 \%)$ \\
Single & $39(11 \%)$ \\
Divorced & $9(2.5 \% 0$ \\
Widow & $6(1.7 \%)$ \\
Education level & \\
Bachelor & $292(81.1 \%)$ \\
Diploma & $34(9.4 \%)$ \\
Institution & $22(6.1 \%)$ \\
Master & $9(2.5 \%)$ \\
PH D. & $3(0.9 \%)$ \\
Position & \\
Primary & $117(32.6 \%)$ \\
Intermediate & $104(29 \%)$ \\
Secondary & $138(38.4 \%)$ \\
Travelling history & $54(15 \%)$ \\
syndrome & $212(60.7 \%)$ \\
Irritable bowel syndrome & $51(14.1 \%)$ \\
\hline &
\end{tabular}

Table 2. Psychosocial characteristics of 362 teachers.

\begin{tabular}{ll}
\hline Character & No\% \\
\hline Absenteeism & $103(28.7 \%)$ \\
Sick leave from the disease & $126(35.1 \%)$ \\
Partner employment & $209(60.6 \%)$ \\
House type & \\
Rent & $199(55.1 \%)$ \\
Own & $162(44.9 \%)$ \\
Salary & \\
$<5000$ Saudi Riyals & $15(4.2 \%)$ \\
$5000-10000$ & $152(42.3 \%)$ \\
$>10000$ & $192(53.5 \%)$ \\
Extra income & $55(15.3 \%)$ \\
Income adequacy & $253(70.5 \%)$ \\
Child care & $196(57.1 \%)$ \\
Smoking & $51(14.1 \%)$ \\
\hline
\end{tabular}




\begin{tabular}{ll}
\hline Character & No\% \\
\hline Stress 1 & \\
Always & $56(15.6 \%)$ \\
Sometimes & $227(63.1 \%)$ \\
Rare & $77(21.4 \%)$ \\
Exercise & \\
Always & $32(8.9 \%)$ \\
Sometimes & $162(45.1 \%)$ \\
Rare & $165(46 \%)$ \\
Sleeping hours & \\
$<6$ hours & $166(46 \%)$ \\
6-9 hours & $192(53.2 \%)$ \\
More than 9 hours & $3(0.8 \%)$ \\
\hline
\end{tabular}

Table 3. Psychosocial factors and irritable bowel syndrome.

\begin{tabular}{|c|c|c|c|}
\hline Character & IBS positive & IBS negative & P-value \\
\hline Salary & & & 0.967 \\
\hline$<5000$ Saudi Riyals & 4 & 4.2 & \\
\hline $5000-10000$ & 44 & 42.1 & \\
\hline$>10000$ & 52 & 53.7 & \\
\hline Extra income & 13.7 & 15.6 & 0.773 \\
\hline Income adequacy & & & 0.325 \\
\hline Yes & 64.7 & 71.4 & \\
\hline No & 35.3 & 28.6 & \\
\hline Residency & & & 0.664 \\
\hline From Tabuk & 56.9 & 60.8 & \\
\hline Outside Tabuk & 43.1 & 39.2 & \\
\hline House type & & & 0.235 \\
\hline Own & 39.2 & 45.8 & \\
\hline Rent & 60.8 & 54.2 & \\
\hline Marital status & & & 0.610 \\
\hline Married & 90.2 & 83.9 & \\
\hline Single & 7.8 & 11.5 & \\
\hline Divorce & 2 & 2.6 & \\
\hline Widow & 0 & 2 & \\
\hline Child care & 64.7 & 55.8 & 0.348 \\
\hline Partner employment & & & 0.696 \\
\hline Yes & 66 & 59.7 & \\
\hline No & 22 & 26.4 & \\
\hline Not applicable & 12 & 13.9 & \\
\hline Absence from work & 52.9 & 24.7 & 0.000 \\
\hline Vacation & 68.6 & 29.5 & 0.000 \\
\hline Smoking & 22 & 13.1 & 0124 \\
\hline Stress continuous & 13.7 & 5.5 & 0.02 \\
\hline Exercise & & & 0.382 \\
\hline Always & 7.8 & 9.1 & \\
\hline Sometimes & 37.3 & 46.4 & \\
\hline Rare & 54.9 & 44.5 & \\
\hline Sleeping hours & & & 0.132 \\
\hline$<6$ hours & 56.9 & 44.2 & \\
\hline $6-9$ hours & 41.2 & 55.2 & \\
\hline More than 9 hours & 2 & 0.6 & \\
\hline
\end{tabular}

Table 4. Associated chronic diseases the study group.

\begin{tabular}{ll}
\hline Disease & No\% \\
\hline Hypertension & $27(7.3 \%)$ \\
Diabetes mellitus & $14(4 \%)$ \\
Bronchial asthma & $14(4 \%)$ \\
Hypertension \&diabetes & $6(1.7 \%)$ \\
Hypertension and Asthma & $1(0.3 \%)$ \\
Diabetes and asthma & $1(0.3 \%)$ \\
Other diseases & $26(7.3 \%)$ \\
\hline
\end{tabular}

\section{Discussion}

In the current study no difference between subjects with irritable bowel syndrome and those without the syndrome regarding income, marital status, and education level, similar to previous studies [6]. A survey carried out in Pakistan [7] concluded the association of irritable bowel syndrome with high income and few years of education in contradiction to the present data.

In the present study no significant statistical difference was evident between subjects with IBS positive and IBS negative as regarding marital status, in contradiction to Andrews et al. [8] who found higher IBS among unmarried patients with the irritable bowel syndrome.

In the current data patients with irritable bowel syndrome were more likely to be absent from work, and took sick leave than those without the syndrome, similar studies [9] concluded that the incremental effect of an IBS diagnosis on six-month absenteeism was estimated to be 3.27 absences greater for persons with IBS.

Researchers found that inadequate sleep increase irritable bowel symptoms the day after, also poor sleep quality increased rectal compliance leading to constipation, furthermore sleep quality as measured by the Pittsburg Sleep Quality Index increased rectal perception to distention [10]. In the current study, no significant statistical difference was evident between the teacher who sleep less than six hours/night and those with regular sleeping hours.

In the present study sleeping less than 6 hours per night is commoner among irritable bowel syndrome patients in accordance with Fujii and Nomura [11] who concluded that psychosocial stressors like history of psychological abuse, less than $6 \mathrm{~h}$ of sleep per night, and irregular diet influenced the progression from an IBS non-consulter to an IBS patient.

Irritable bowel syndrome exhibit significant co-morbidities between mood alteration in workers and patients with unipolar depression are more prone to IBS-like symptoms. The autonomic nervous system, hypothalamic-pituitary axis, and genetic factors participate in gastrointestinal tract alterations in workers [12] moreover, change in the intestinal microbiota can interact with the immune and nervous systems leading to GIT symptoms [13]. In the present study continuous stress was commoner among participants with irritable bowel syndrome with significant statistical difference confirming the above observation. Previous literature concluded that the most important factors in IBS are catastrophizing, and somatization and the effects of all other psychological variable seem to be explained by these two elements [14].

\section{Conclusion}

Patients with IBS were more likely to suffer from stress, take sick leave, and had more absence days from work than those without the syndrome. Screening for anxiety and depression and referral for cognitive behavioral therapy could be an essential part of IBS care. 


\section{References}

[1] Longstreth GF, Thompson WG, Chey WD, Houghton LA, Mearin F, Spiller RC. Functional Bowel Disorders. In: Drossman DA, Corazziari E, Delvaux M, Spiller RC, Talley NJ, et al., editors. Rome III: The Functional Gastrointestinal Disorders.3rd ed. McLean, VA: Degnon Associates Inc; 2006. pp. 487-555.

[2] Drossman DA. The functional gastrointestinal disorders and the Rome III process. In: Drossman DA, Corazziari E, Delvaux M, Spiller R, Talley NJ, et al., editors. Rome III: the functional gastrointestinal disorders.3rd ed. McLean, VA: Degnon Associates Inc; 2006. pp. 1-30.

[3] Sandler RS, Everhart JE, Donowitz M, et al. The burden of selected digestive diseases in the United States. Gastroenterology 2002; 122: 1500 .

[4] statement on the management of irritable Brandt LJ, Chey WD, Foxx-Orenstein AE, Schiller LR, Schoenfeld PS, Spiegel $\mathrm{BM}$, et al. An evidence-based position bowel syndrome. Am J Gastroenterol.2009 Jan.104 Suppl 1: S1-35.

[5] Qin HY, Cheng CW, Tang XD, Bian ZX. Impact of psychological stress on irritable bowel syndrome. World J Gastroenterol. 2014 Oct 21; 20 (39): 14126-14131.

[6] Minoch A, Johnson WD, Abell TL, Wigington WC. Prevalence, Socio demography, and QualitLife of Older Versus Younger Patients with Irritable Bowel Syndrome: A Population-Based Study. Digestive Diseases and Sciences March 2006, Volume 51, Issue 3, pp 446-453

[7] Husain N, Chaudhry IB, Jafri F, Niaz SK, Tomenson B, Creed F. A population-based study of irritable bowel syndrome in a
non-Western population. Neurogastroenterol Motil. 2008 Sep; 20 (9):1022-9.

[8] E. B. Andrews; S. C. Eaton; K. A. Hollis; J. S. Hopkins; V. Ameen; L. R. Hamm; S. F. Cook; P. Tennis; A. W. Mangel. Prevalence and Demographics of Irritable Bowel Syndrome: Results from a Large Web-Based Survey. Aliment Pharmacol Ther. 2005; 22 (10):935-942.

[9] Zacker C, Chawla AJ, Wang S, Albers LA. Absenteeism among employees with irritable bowel syndrome. Manag Care Interface. 2004 May; 17 (5): 28-32.

[10] Kok-Ann Gwee. Disturbed Sleep and Disturbed Bowel Functions: Implications for Constipation in Healthy Individuals. J Neurogastroenterol Motil.2011 Apr; 17 (2): 108-109

[11] Fujii Y, Nomura S. A prospective study of the psychobehavioral factors responsible for a change from nonpatient irritable bowel syndrome to IBS patient status. Biopsychosoc Med. 2008; 2: 16.

[12] María-Raquel Huerta-Franco, Miguel Vargas-Luna, Paola Tienda, Isabel Delgadillo-Holtfort, Marco Balleza-Ordaz, andCorina Flores-Hernandez. Effects of occupational stress on the gastrointestinal tract. World J Gastrointest Pathophysiol.2013 Nov 15; 4 (4): 108-118.

[13] Ringel Y, Maharshak N. Intestinal microbiota and immune function in the pathogenesis of irritable bowel syndrome. Am J Physiol Gastrointest Liver Physiol. 2013; 305: G529-G541.

[14] Miranda A. L. van Tilburg, Olafur S. Palsson, PsyD, and William E. Whitehead. Which psychological factors exacerbate Irritable Bowel Syndrome? Development of a comprehensive model. J Psychosom Res.2013 Jun; 74 (6): 486-492. 